Article

\title{
Does Traditional Guanxi Still Matter in Social Commerce: An Empirical Study in Taiwan
}

\author{
Wen-Kuei Wu \\ Department of Business Administration, Chaoyang University of Technology, Taichung 413310, Taiwan; \\ wenkuei@cyut.edu.tw
}

Received: 16 October 2019; Accepted: 19 October 2020; Published: 20 November 2020

\begin{abstract}
This study aims to explore if traditional guanxi facets (i.e., ganqing, renqing and mianzi) between buyer and seller affect buyer's trust in seller, recommendation and purchase intention in social commerce. It also investigates the mediating effects of recommendation intention and trust in seller on the relationship between guanxi facets and purchase intention. This study used an online survey in Taiwan and the partial least squares (PLS) model to test the hypotheses. Drawing on a sample of 323 respondents in Taiwan, the results show that (a) ganqing, renqing and trust in seller have positive effects on recommendation intention, (b) all guanxi facets exert positive effects on trust in seller, (c) ganqing and mianzi contribute to recommendation intention via trust in seller, (d) renqing benefits directly purchase intention but also via recommendation intention, and (e) trust in seller facilitates purchase intention via recommendation intention. This study might be the first to investigate the vital roles of traditional guanxi facets, rather than swift guanxi, in social commerce. This study also clarifies the mediating effects of buyer's recommendation intention and trust in seller on transferring traditional guanxi facets into purchase intention.
\end{abstract}

Keywords: guanxi; ganqing; renqing; mianzi; social commerce

\section{Introduction}

Due to the proliferation of $4 \mathrm{G}$ communication technologies and online social communities, it is easy to start up a conversation or discussion, as well as transfer information on social media. For those who have just begun their personal selling business and have not yet many connections or are not involved in many social networks, social commerce, which allows online communicating and selling items within social networks, can be the first choice. As such, the effects of the buyer-seller relationship and sharing shopping information with friends on online purchasing through social commerce have emerged as critical research topics [1,2]. Li, Liang, and Li [3] have confirmed that the buyer-seller friendship quality (an analogy of tie strength, such as good friends, simple friends and strangers) has been playing a critical role in Chinese social commerce. However, based on the perspective of Chinese guanxi (i.e., a personal connection between two people in Chinese culture), the friendship quality is just a subset of guanxi features and it cannot comprehensively measure the multiple guanxi facets between Chinese counterparts, i.e., ganqing (feeling or affection), renqing (sentiment, empathy or reciprocity) and mianzi (face, social status or prestige) [4]. In addition, as an extension of traditional guanxi, the concept of swift guanxi has been adopted and confirmed to drive consumers' behavioral or repurchase intentions due to its swift nature in online transactions $[5,6]$. Nevertheless, using swift guanxi to capture the properties of the buyer-seller relationship in social commerce could overlook some important traditional guanxi facets' effects since buyer-seller interaction in a social commerce context is not necessarily so "swift" and that could be built or facilitated on some common or ascribed guanxi bases (e.g., school mates, colleagues, and acquaintances) [7], which in turn might boost the traditional guanxi thought. Given the emergence of social commerce, which is a combination of 
social media and e-commerce [2], more and more marketers discuss using social media as a tool for communicating instead of actually contacting consumers and building a long-term relationship through the social media [8]. Still, most research focuses on using social media in business-to-business sales $[9,10]$ or a B2C (business-to-consumer) sales context [11], and rare research incorporates the impact of traditional guanxi facets in social commerce.

Considering the research gaps in the role of traditional guanxi facets between Chinese counterparties in the field of social commerce, this study aims to investigate whether the effects of guanxi facets, which are derived from traditional guanxi concepts [4], still work in social commerce. The results can shed more light on how each of the buyer-seller guanxi facets affects social media engagement and sales in social commerce, and which in turn enables sellers to cultivate guanxi more efficiently and effectively. Besides, due to the potential effects of social referral or recommendations to friends $[12,13]$ in social commerce and trust in the seller in the context of the Chinese culture [14], it is worthwhile to compare the effects of buyer-seller guanxi facets, recommendation intention and trust in seller on purchase intention. This study also examines if the buyer's recommendation intention and trust in the seller play the critical mediating roles in social commerce. This study first reviews traditional guanxi and swift guanxi related literature, then proposes a research model to investigate how the buyer-seller guanxi facets, including ganqing, renqing, and mianzi, affect recommendation intention, trust in seller and purchase intention on social media. The survey data come from Taiwan, where-like China-there exists a society influenced deeply by Confucianism and guanxi practices. According to results, the theoretical implications and practical suggestions are provided for the seller in social commerce to build transaction relationships with their friends without damaging the friendships on social media.

\section{Literature Review}

\subsection{Traditional Guanxi and Swift Guanxi}

Guanxi refers to particularistic interpersonal relationships, connections, ties or networks $[15,16]$. In Chinese words, guanxi is a composite word including "guan" (gates) and " $x i$ " (connections or relationships). The former is related to ascribed personal relationship bases and the latter is the result of historical or continuous interactions. The unique features of guanxi are rooted in traditional Chinese society, which was predominantly built around the family and ruled by Confucianism. These cultural beliefs emphasize the interdependence of social connections and mutual obligations, rather than strong or codified laws. Briefly speaking, guanxi implies personal connections and mutual obligations between parties, and it operates on personal, familial, social, business and political levels. Guanxi can be employed as a governance mechanism [17], social capital [18] and effective conduits for entrepreneurial success in the Taiwanese business context $[19,20]$. Over the last three decades, guanxi-related research has become more widespread, and many facets of guanxi and their impacts have been studied [21,22].

Guanxi can be largely classified into three identical facets, namely ganqing, renqing, and mianzi [4]. Ganqing refers to the sense of a social relationship and an emotional attachment between two people (Wang, 2007). It reveals the degree of emotional understanding, feelings and the willingness to take care of each other under any circumstances [15,23]. Ganqing reflects the affective side of guanxi. Only continuous social interactions and activities together can help develop ganqing, such as sharing an inner feeling and demonstrating personal care through gifts/favors giving, dining and participating in social activities [21]. Thus, ganqing also presents the level of adaption. For example, for Chinese people, a stranger is likely to become their close friends/mates because of not just the perceived commonalities or ascribed bases but also the continuous exchanging information, favors and emotional attachments. Historical and continuous interactions between parties are the most crucial bases for a deep ganqing. If the guanxi between parties is rooted in some commonalities (tong, e.g., colleagues, classmates, relatives, or family) and historical/continuous interactions (lao, e.g., old friends), they treat each 
other like iron friends or confidantes [24]. Without ganqing, which results from historical/continuous interactions, they treat each other like cold acquaintances.

Renqing consists of reciprocity and empathy [4]. A person possesses renqing if he/she has empathy towards other's emotions and feelings and willingness to help. On the other hand, if one receives a drop of beneficence from other people, one should return to them a fountain of beneficence [4]. Such reciprocity is emphasized in the Confucian philosophy [25]. Therefore, renqing is practiced by showing empathy and exchanging favors toward the counterparty [26]. Renqing also results from the ascribed guanxi base or the commonality, which leads to different interaction rules. For example, jia-ren-based guanxi (relationships with family members) follows the obligation rule, in which favor exchanges are often considered unconditional and moral [27]. Shou-ren-based guanxi (relationship with acquaintances) follows the reciprocity rule, in which medium degrees of favor exchange, common social identities, and sentiments are cultivated [28]. Sheng-ren-based guanxi (relationships with strangers) follows the instrumentality rule, in which the norm of equity, personal gain and loss, and utilitarian stances are major considerations [29]. Due to the reciprocity or obligation rule, renqing usually is used to facilitate better coordination within the relationship based on the ascribed guanxi base or the commonality.

Mianzi implies one's respect, status, prestige and moral reputation in Chinese society $[4,30]$. People in Chinese society typically gain mianzi by building many interpersonal connections and achieving a higher social status [22,31]. They care about if they and their relatives have been saved/given mianzi. They also try to save the mianzi of others since making others lose face is considered as physically attacking others, which in turn destabilizes or ends the guanxi between parties [32]. Therefore, mianzi-saving/giving is a critical factor for maintaining and intensifying guanxi [21]. Through the mianzi-saving/giving, social influence is accessed, and other's requests are satisfied. For example, if one feels the need to save the counterparty's mianzi or give a mianzi to the counterparty, in order to keep or strengthen the guanxi between parties, the one will positively respond to the counterparty's offers or requests.

Past research does not pay attention to if the traditional guanxi works in social commerce. Due to the advent of online shopping technologies, the concept of traditional guanxi has been extended to reveal the buyer's perception of a swift formed interpersonal relationship with a seller in the online marketplace. Qu, Pavlou, and Davison [5] propose the concept of swift guanxi to conceptualize the buyers' perception of a swiftly formed interpersonal relationship with a seller, which roots from the literature on traditional guanxi and consists of mutual understanding, reciprocal favors, and relationship harmony in the context of online marketplaces. Qu et al. empathized that the three features of swift guanxi help ensure transactions in online marketplaces where fair arbitration and face-to-face contact are difficult to achieve. Researchers adopt the concept of swift guanxi to portray that online buyer-seller guanxi is based on the four differences between traditional and online buyer-seller relationships, i.e., swift relationship duration, lower resource dependence, equal status, and the aid of communication technology [1,2,5]. Most extant empirical studies adopting the swift guanxi concept are conducted on C2C (consumer-to-consumer) e-commerce platforms/websites that add social networking tools to facilitate social interaction, such as Taobao and Yahoo! Online auction [5,14]. Some studies are conducted on WeChat or Weibo to examine Chinese consumer shopping intention in social commerce $[2,33]$.

Nevertheless, it is doubtful if the buyer-seller guanxi is swift in social commerce, especially in social media-based platforms, such as Facebook, Instagram or Line. First, in comparison with traditional C2C e-commerce platforms, social media-based platforms can provide more emotional benefits [34], more social experience [35], and social relationships that influence the purchase decision [36]. Without long-term interactions on social media, these social relationships, social and emotional experiences cannot be built. Second, traditional guanxi reveals a significant cultural value dominating Chinese people's behavior, and social media appears to be the modern gateway to the anciently and culturally unique construct of guanxi [37]. Despite traditional guanxi being based on face-to-face communication, 
the aid of web-based communication technologies and social media can compensate for the limitation of face-to-face interaction and achieve effective communication between counterparties in a social network [9]. Social media platforms have been used by salespeople to enhance the performance of sales tasks [38], reach new buyers and develop deeper relationships with customers $[8,38]$. Thus, social media technologies can deepen and expand the buyer-seller guanxi but cannot transform it into a swift relationship. Third, consumer engagement in online social commerce is due to the informational and emotional support [2], and that just highlights the consumer's resource dependences and unequal status because consumers need these supports. As stated above, the buyer-seller guanxi is not becoming swift in the context of social commerce; on the contrary, it is likely to be strengthened due to the aid of social media platforms. Thus, adopting the concept of swift guanxi to portray the online buyer-seller guanxi in social commerce could not be appropriate. Instead, swift guanxi tends to be built on e-commerce websites that add social networking tools to facilitate social interactions in the form of online reviews [1]. Thus, this study aims to investigate the effect of traditional guanxi, rather than swift guanxi, on purchase intention in the social commerce context.

Many studies have confirmed the relationship quality or tie strength between buyers and sellers, which is the consequence of guanxi activities in the Confucian-rooted society, tends to increase purchase intention in social commerce $[39,40]$. However, few studies look into the role of guanxi facets. Based on the perspective of guanxi investment [21], ganqing, renqing, and mianzi represent different types of relationship investment in a guanxi building and maintaining. Thus, examining the separate effect of guanxi facets (investment) is needed, since it will help sellers in social commerce improve the buyer's trust in the seller, recommendation and purchase intention through identifying which buyer-seller guanxi facet needs to be enhanced.

\subsection{Trust and Recommendation in Social Commerce}

Trust plays a major role in commercial transactions, especially in reducing the transaction-related risk, controlling opportunistic behavior and promoting successful e-commerce and social commerce [35]. Owing to the lack of face-to-face interactions and a massive amount of user-generated content in social commerce, the high uncertainty may halt the progress of transactions in social commerce [41] and that can be resolved by trust-building and improved experience with exchange parties [42]. Thus, trust in a seller and trust-getting information plays crucial roles and needs to be developed over time after the first transaction [14,43]. Although trust is a multidimensional term with different definitions [36], trust can be regarded as a buyer's psychological expectation or confidence that a seller will not have opportunistic behaviors, which are based on a buyer's beliefs including the seller's ability, integrity and benevolence [2,5]. Without a doubt, a buyer's trust in a seller leads to purchase intention and actual purchasing behavior [5,42].

The advent of social commerce prompts researchers to investigate consumer-generated social recommendations and referrals due to the potential social influences of a friend on social networking sites (SNS) [13]. Although word of mouth (WOM) has been confirmed to change consumer attitudes about a product and enhance sales, most WOM is focusing on online product reviews and that matters only when consumers already have purchase intention and have read the reviews. By contrast, consumer-shared social referrals and recommendations have become vital ways to share information to pursuit social interactions with [44] and demonstrate social influences among consumers of social networking [45]. In the social commerce context, consumers are allowed to deliver recommendations or referrals to their specific friends, indicating that the marketers can access social media users' social activity (e.g., recommendations or referrals) to present target consumers with the products or services that could match their tastes [33].

\section{Research Model and Hypotheses Development}

According to the previous literature review, ganqing, renqing and mianzi could positively influence trust in seller and recommendation intention, whereas trust in seller facilities recommendation intention. 
Trust in seller and recommendation intention also positively increase purchase intention. Figure 1 presents the proposed hypotheses and research model in this research.

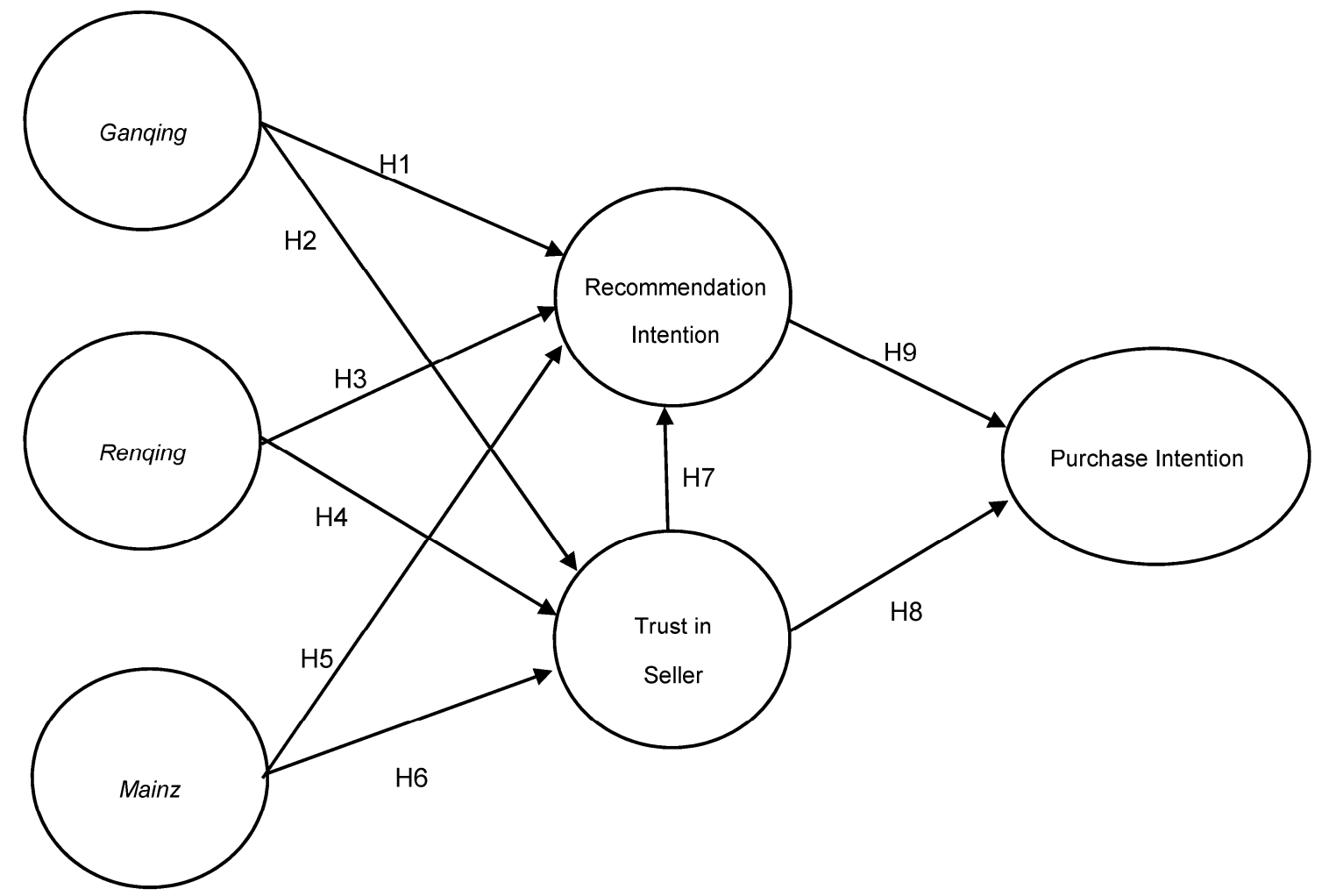

Figure 1. Research model.

Ganqing is the emotional element in the formation of guanxi [46] and used to describe the quality of a relationship between two parties (Yen, Barnes, and Wang, 2011). The higher the level of buyer-seller ganqing, the more cooperative and willing both parties are to engage in a continuous exchange of mutual help and favor [23]. As such, the buyer's recommendation intention of seller's posts on social media will be higher. Besides, through continuous social interactions or activities together, ganqing will be strengthened and each other's trustworthiness will be cultivated by the long term and continuous exchange of favors (Chen, 1995) and adaptations (Wong, 1998). A higher level of ganqing also reflects a strong social tie that bonds the parties by the frequent interactions, emotional intensity, intimacy (mutual confiding), and reciprocal exchanges [47]. A strong social tie helps reduce buyer's uncertainty on the social commerce platform [34]. Thus, the higher the buyer-seller ganqing, the higher the buyer's trust in the seller. Accordingly, the following hypotheses are proposed:

Hypothesis 1. The buyer-seller ganqing is positively related to the buyer's recommendation intention of the seller's persuasive messages on social media.

Hypothesis 2. The buyer-seller ganqing is positively related to the buyer's trust in seller.

Through showing empathy and exchanging favors toward the counterparty, renqing plays as a useful mechanism to create obligation of reciprocity, commitment and provide mutual assistance in time of need between parties $[4,26,48]$. Perceiving a high level of buyer-seller renqing, indicates a feeling of owing each other a favor or feeling the obligation of providing each other with some help, satisfying the counterparty's expectation of reciprocity or showing empathy/benevolence toward the seller, which in turn makes the buyer willing or cooperative to help the seller with recommendations or purchase behaviors. On the other hand, as mentioned previously, renqing perception may be 
based on the ascribed guanxi bases or the commonalities between parties, such as family members or acquaintances. People in the ascribed guanxi or commonality network are usually treated as zi-ji-ren (insiders) and considered as being trustworthy [49]. In addition, social referral causes one's social friends to purchase products/services via social commerce due to the effects of social influence, such as the process of identification (to maintain the desired relationship) and internalization (to show the congruence or similarity between parties' values) [13]. Renqing plays the similar function as social identification since renqing perception facilitates a buyer to show his/her empathy and support toward his/her friend (seller) to maintain the relationship, and to show his/her trust in his/her friends who are being treated as zi-ji-ren (insiders). Thus, the following is hypothesized:

Hypothesis 3. The buyer-seller renqing is positively related to the buyer's recommendation intention of the seller's persuasive messages on social media.

Hypothesis 4. The buyer-seller renqing is positively related to the buyer's trust in seller.

To give/save Mianzi means giving prestige, avoiding public criticism, making decent compliments toward counterparties or satisfying counterparties' needs, which in turn enhances counterparties' self-esteem and maintains guanxi with counterparties [21]. Causing counterparties to lose face will damage their self-esteem [4]. Therefore, when people receive their friends' (i.e., sellers) persuasive messages on social media, due to the mianzi concern, people will show their appreciation on the posts and advocate them to other friends. Otherwise, the guanxi between parties may be damaged due to causing the counterparty to lose face. From the perspective of social influence, saving/giving mianzi for each other could be the process of internalization, which occurs when people adopt the opinion of peers based on congruence or similarity between parties on the social commerce platforms [13]. The embedded meaning of mianzi is also that one's own verbal promise must be honored when interacting with others to earn/keep personal social credits, status, and respect for mutual exchanges. Then, to preserve, save or give seller's mianzi on social media also insinuates the buyer's acknowledgment of seller's trustworthiness and credibility, and indicates buyer's willingness to trust the seller [50].

Hypothesis 5. The buyer's concern over the seller's mianzi is positively related to the buyer's recommendation intention of the seller's persuasive messages on social media.

Hypothesis 6. The buyer's concern over the seller's mianzi is positively related to the buyer's trust in seller.

People in Chinese society prefer dealing with old friends in their guanxi network, and to avoid outsiders (wai-ren) to prevent losses due to the counterparty's trustworthiness and credit [51]. The trust in seller results from a strong social tie, which in turn increases the recommendation and purchase intention on the social media platform [47,52]. The higher the trust in the seller, the higher the recommendation intention of the seller's persuasive messages and the purchase intention on social media. The following is hypothesized:

Hypothesis 7. The buyer's trust in seller is positively related to the buyer's recommendation intention of the seller's persuasive messages on social media.

Hypothesis 8. The buyer's trust in seller is positively related to the purchase intention on social media.

Consumer's referrals or recommendations have been very influential and helpful for eWOM (electronic word-of-mouth) advertising on social network websites because they come from a trustworthy source and from first-hand experiences [53]. However, to respond to the seller's persuasive messages on social media by only referrals and recommendations instead of purchase behavior 
might damage the seller's mianzi. Social connections are the main emphasis of online social media communities [54]. The group identity or commitment to follow the common norms, values and beliefs serves as a social-cognitive schema. To keep the consistency between attitudes, promises, social images (mianzi), and behaviors to each other in the guanxi network, a consumer's high level of recommendation intention will lead to a high level of purchase intention on social media.

Hypothesis 9. The buyer's recommendation intention of the seller's persuasive messages is positively related to the buyer's purchase intention on social media.

This study also considers the potential effect of purchase-decision involvement (PDI). Involvement refers to a person's perceived relevance of the focal object based on inherent needs, values, and interests [55]. The Elaboration Likelihood Model (ELM) [56,57] suggests that a product or argument is classified as high involvement if it engenders central or elaborate cognitive processing. People with a high level of PDI are expected to pay more attention to product information and to evaluate the persuasive messages in depth. On the contrary, people with a low level of PDI generally evaluate products following a peripheral route and require a less cognitive resource to process the persuasive messages. Therefore, this study considers the PDI to be an important control variable and examines its potential effect on a buyer's purchase intentions.

\section{Research Method}

\subsection{Instrument Development}

To test the research model and hypotheses, a questionnaire is developed to measure the research variables including buyer-seller guanxi facets (i.e., ganqing, renqing, and mianzi), trust in seller, recommendation intention, purchase intention, and PDI by referring to existing literature and well-developed scales from previous studies. All measures used in this research and related literature are listed in Appendix A. Following the approach of Ou et al. [5], the trust in seller was measured in a component-based and formative measurement (i.e., ability, integrity, and benevolence) instead of the reflective way that was used in the other research variables. The original version was designed in English and translated to Chinese, then another Taiwanese researcher back-translated the questionnaire to validate the correction of translation. The Chinese version was refined through insights gleaned from three experts in Taiwan including a professor of marketing management, a practical marketer on shopping websites and a salesperson experienced in using social media to determine their validity and clarity. All items were evaluated using a five-point Likert scale ranging from 1 (strongly disagree) to 5 (strongly agree).

\subsection{Data Collection}

A pre-test was conducted before the final data collection by sampling 36 participants who are Taiwanese students studying for an MBA from a university in Taiwan, and all the items satisfied the validity and reliability threshold value of the constructs. The survey data were gathered from a voluntary online survey platform. A lottery draw was offered for one TWD 2000 (USD 64) prize, two TWD 1000 (USD 32) prizes and four TWD 500 (USD 16) prizes to encourage participation and asked participants to spread the survey to their friends, families or people who they have known. To ensure that all participants had experience of being persuaded/convinced by friends on social media, an initial screening question was asked in the beginning of the questionnaire, which is: In the last one year, do you have any experience of receiving persuasive messages from people who you know on social media (e.g., Facebook, Line or Dcard, etc.), and being persuaded to buy the products or services? During the three weeks' factual data collection period, a total of 362 respondents answered the online survey questionnaires, and the number of usable questionnaires was 323 , forming an effective response rate of 89.22 percent. 
Table 1 describes the demographics of these respondents. According to the report released by We Are Social [58], the most popular social media in Taiwan is Facebook (FB), which has been used by $80 \%$ of Taiwanese people, and the majority (46\%) of FB users were between 18 and 34 years old. In every class interval of age, the percentage of the male is slightly greater than female. The demographics of the respondents in this study had no significant differences with the We Are Social's recent report. Therefore, the sample appears to be reasonably representative of social media users in Taiwan.

Table 1. Sample demographics.

\begin{tabular}{|c|c|c|c|}
\hline Measure & Item & Frequency & Percentage \\
\hline \multirow{2}{*}{ Gender } & Male & 170 & $51.93 \%$ \\
\hline & Female & 153 & $48.07 \%$ \\
\hline \multirow{3}{*}{ Age } & 18 or below & 13 & $4.00 \%$ \\
\hline & $19-40$ & 236 & $73.10 \%$ \\
\hline & 41 or over & 74 & $22.90 \%$ \\
\hline \multirow{4}{*}{ Educational level } & High School or below & 32 & $9.90 \%$ \\
\hline & College/University & 153 & $47.40 \%$ \\
\hline & Master & 121 & $37.50 \%$ \\
\hline & Ph.D. & 17 & $5.20 \%$ \\
\hline \multirow{5}{*}{ Monthly income } & Less than NTD 20,000 (USD 640) & 126 & $39.01 \%$ \\
\hline & NTD 20,000 30,000 (USD 640 960) & 116 & $35.91 \%$ \\
\hline & NTD 30,000 40,000 (USD 960 1280) & 50 & $15.48 \%$ \\
\hline & NTD 40,000 50,000 (USD 1280 1600) & 18 & $5.57 \%$ \\
\hline & More than NTD 50,000 (USD 1600) & 13 & $4.02 \%$ \\
\hline \multicolumn{4}{|c|}{ Type of products and services } \\
\hline \multirow{3}{*}{\multicolumn{2}{|c|}{$\begin{array}{l}\text { Accessories, cosmetics, footwear, handbags, etc. } \\
\text { Electronic products (smartphones, cameras, laptops, tablets, software, etc.) } \\
\text { Foods }\end{array}$}} & 132 & $40.87 \%$ \\
\hline & & 47 & $14.55 \%$ \\
\hline & & 22 & $6.81 \%$ \\
\hline \multicolumn{2}{|l|}{ Tourist services } & 7 & $2.17 \%$ \\
\hline \multicolumn{2}{|c|}{ Books and newspapers } & 20 & $6.19 \%$ \\
\hline \multicolumn{2}{|c|}{ Cosmetics and Accessories } & 41 & $12.69 \%$ \\
\hline \multicolumn{2}{|c|}{ Educational services and goods } & 5 & $1.55 \%$ \\
\hline \multicolumn{2}{|c|}{ Financial services (Insurance, stocks, debentures, etc.) } & 11 & $3.41 \%$ \\
\hline \multicolumn{2}{|c|}{ Healthcare and social services } & 24 & $7.43 \%$ \\
\hline \multicolumn{2}{|c|}{ Household commodities (TVs, washing machines, fridges, etc.) } & 7 & $2.17 \%$ \\
\hline \multicolumn{2}{|c|}{ Repair services } & 3 & $0.93 \%$ \\
\hline \multicolumn{2}{|l|}{ Others } & 4 & $1.24 \%$ \\
\hline \multicolumn{2}{|l|}{ Total } & 323 & $100.00 \%$ \\
\hline
\end{tabular}

\section{Results}

The partial least squares (PLS) model was used as the primary statistical technique to test the research framework and hypotheses. PLS is a useful tool in complex path models in an explorative manner [59], particularly for this research that involves developing a new measurement of guanxi facets and structural paths. PLS also can handle both reflective and formative constructs simultaneously [60]. Besides, PLS uses non-parametric inference methods (i.e., bootstrapping) and it is not limited by restrictive assumptions imposed by LISREL (LInear Structural RELations) -like models [61]. Furthermore, it uses the resampling procedures packaged in the SmartPLS software (version 3.2) to calculate the standard deviation, generate an approximate $t$-statistic, and overcome the disadvantage of non-parametric methods of having no formal significance tests for the estimated parameters [62].

\subsection{Measurement Model}

To purify the measures and assess reliability in PLS path modeling, eight items were dropped because of cross loading, incorrect loading, and lower indicator loading. Scale statistics (correlations 
and descriptive statistics) are presented in Table 2. Appendix A also presents the cronbach's alpha, composite reliability and average variance extracted (AVE) of each reflective construct. Bootstrapping with 2000 resamples was performed for the structural model of PLS estimation. The bootstrap-based inference statistics showed that SRMR (Standardized Root Mean Residual) was 0.066 and was less than the threshold of 0.08 , indicating an acceptable fit for the measurement model. All composite reliability coefficients attained the acceptable 0.7 level. The AVE values for all reflective constructs were greater than 0.5 (see Table 2), supporting the convergent validity of the measurement items [63]. The multi-collinearity of the formative construct-trust in seller, was also examined. The formative indicator weights range from 0.151 to 0.509 and exert distinct effects. All the variance inflation factors (VIFs) range from 2.193 to 2.792 and are less than the threshold of 10. The multicollinearity is not a problem in conceptualizing trust in seller to be a formative construct.

Table 2. Descriptive statistics and discriminant validity assessment of the measurement model.

\begin{tabular}{|c|c|c|c|c|c|c|c|}
\hline Measure & 1 & 2 & 3 & 4 & 5 & 6 & 7 \\
\hline 1. Ganqing & 0.906 & & & & & & \\
\hline 2. Renqing & 0.835 & 0.851 & & & & & \\
\hline 3. Mianzi & 0.655 & 0.655 & 0.878 & & & & \\
\hline 4. Trust in seller & 0.710 & 0.684 & 0.676 & 1 & & & \\
\hline 5. Recommendation intention & 0.723 & 0.712 & 0.621 & 0.823 & 0.896 & & \\
\hline 6. Purchase intention & 0.492 & 0.56 & 0.438 & 0.525 & 0.637 & 0.846 & \\
\hline 7. Purchase-decision Involvement & -0.3 & -0.257 & -0.305 & -0.281 & -0.186 & 0.14 & 0.867 \\
\hline Mean & 3.119 & 2.965 & 3.311 & 3.252 & 2.977 & 2.956 & 2.878 \\
\hline Standard deviation & 1.249 & 1.288 & 1.163 & 1.11 & 1.19 & 1.037 & 1.148 \\
\hline
\end{tabular}

Note: Diagonal elements are the square roots of the average variance extracted (AVE) statistics. Sub-diagonal elements are the correlations among latent variables calculated in the PLS.

\subsection{Common Method Bias}

Considering all data were self-reported and from a single source, several tactics were adopted to eliminate the potential common method bias (CMB) [64]. As mentioned previously, the meaning of each item of the questionnaire was first refined through insights from three experts to ensure content validity and reduce item ambiguity. Second, respondents were informed that their anonymity would be protected to reduce evaluation apprehension and social desirability. Participants were also not allowed to change previous answers or change the sequences of answering. The Harman's single-factor test [65] shows that the first factor explains $45.69 \%$ of the variance, which is less than $50 \%$ of the total variance, indicating a single factor neither emerges nor accounts for the majority of the covariance of the variables and CMB does not appear to be a problem [66]. The VIFs were lower than 3.3 in the full collinearity test, revealing that the CMB in this study can be ruled out [67].

\subsection{Structural Model}

The hypotheses of the proposed research model were tested by checking the significance level of each path coefficient in PLS analysis. As shown in Figure 2, the overall explanatory power $\left(\mathrm{R}^{2}\right)$ indicates that the model accounts for $74.0 \%, 59.9 \%$ and $55.8 \%$ of recommendation intention, trust in seller and purchase intention, respectively. The $\beta$ coefficients of the model showed that the ganqing ( $\beta=0.149$, $p<0.05)$, renqing $(\beta=0.185, p<0.01)$ and trust in seller $(\beta=0.590, p<0.000)$, rather than mianzi, facilitate recommendation intentions. H5 is not supported. Mianzi does not influence recommendation intention. The recommendation means the actions of putting forward (someone or something) with approval as being suitable for a particular purpose, indicating buyers must be willing to endorse and guarantee the products or services not just pay lip services. Apparently, a buyer's willingness to endorse and guarantee is due to ganqing, renqing and trust in seller, rather than mianzi. It is also possible that buyers could use clicking like or giving some positive comments instead of recommendations to keep the seller's mianzi, or there is even not so much mianzi needed to be saved in social commerce 
context. However, these speculations still merit further investigation. The results are also different from the findings of Pescher, Reichhart, and Spann [12] which demonstrated that tie strength has a negative influence on the reading and decision to refer stages. This study confirms that ganqing and renqing have a positive influence on recommendation intention. The different interpretations and perspectives of the buyer-seller relationship might be the major causes. Notably, mianzi ( $\beta=0.349$, $p<0.001)$ and ganqing $(\beta=0.328, p<0.001)$ exert more effects than renqing ( $\beta=0.172, p<0.05)$ on trust in seller, indicating the critical role of mianzi concern and ganqing in acknowledging trust in seller between parties. According to the results, the traditional guanxi facets do affect differently a buyer's recommendation intentions and trust in seller, and the seller should identify their individual effects and cultivate them to improve effectiveness in social commerce.

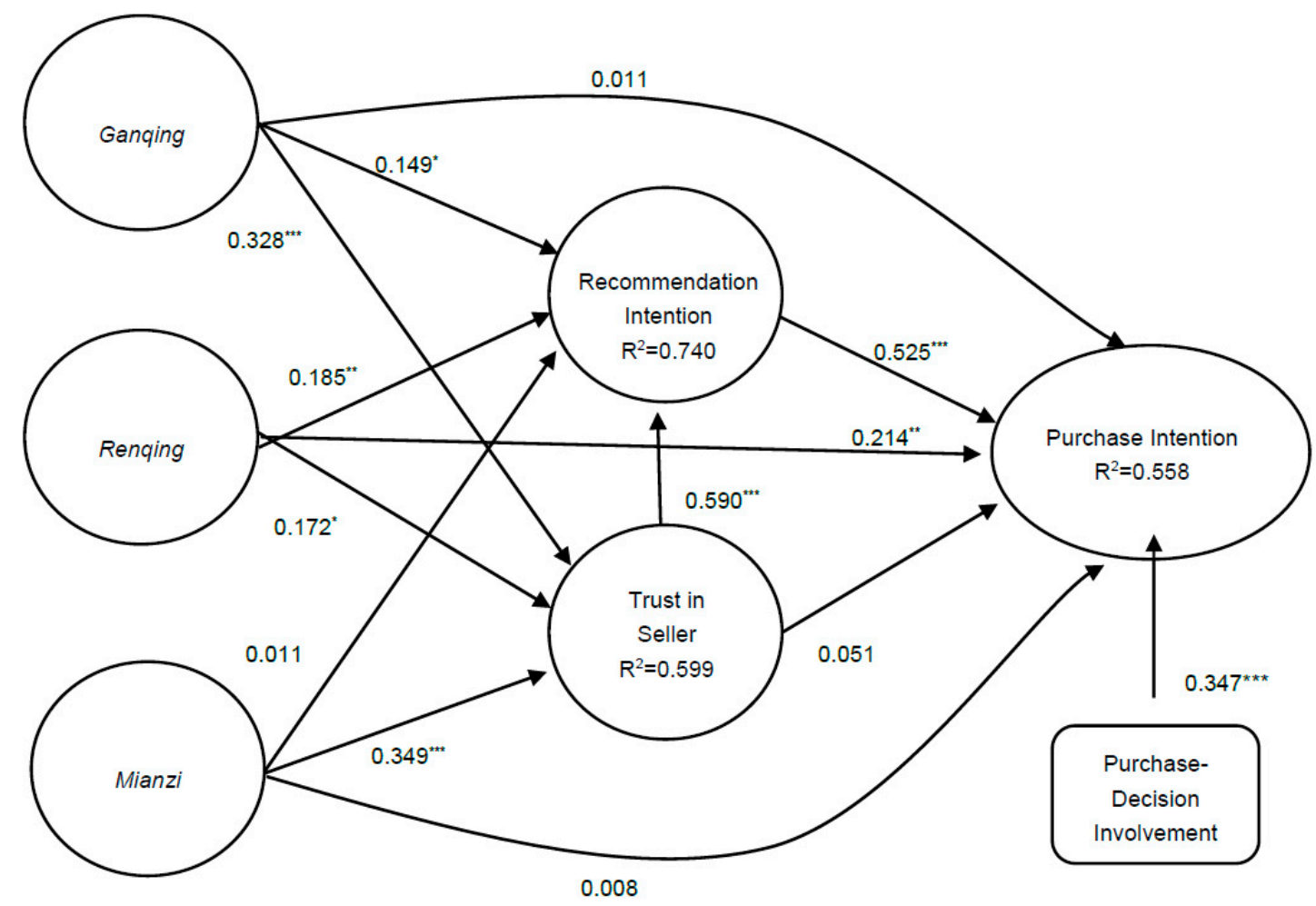

Figure 2. Path diagrams $\left({ }^{* *} p<0.001 ;{ }^{* *} p<0.01{ }^{*} p<0.05\right)$.

A mediator analysis was conducted to test the potential mediating effects of recommendation intention and trust in seller between guanxi facets and purchase intention [68]. As shown in Table 3, trust in seller significantly and positively mediated the relationships of ganqing $\rightarrow$ recommendation intention (indirect effect $=0.194$, $t$-value $=3.332, p$-value $<0.001$ ) and mianzi $\rightarrow$ recommendation intention (indirect effect $=0.206, \mathrm{t}$-value $=4.841, p$-value $<0.001$ ). Recommendation intention significantly and positively mediated the relationship of renqing $\rightarrow$ purchase intention (indirect effect $=0.097$, $\mathrm{t}$-value $=2.838, p$-value $<0.01$ ). Dong and Wang [47] suggest that both strong and weak social ties are all positively related to repurchase intention in online social commerce. The findings further confirm that the Chinese social ties-ganqing and mianzi concern—contribute to recommendation intention via trust in seller, and renqing contributes to purchase intention via recommendation intention. The results also indicate that recommendation intention significantly and positively mediated the relationships of trust in seller $\rightarrow$ purchase intention (indirect effect $=0.310$, $t$-value $=5.560, p$-value $<0.001$ ), which extend the findings of Chong, Lacka, Li and Chan [69], Ou et al. [5], and Lin et al. [2]. Recommendation intention almost replaces the effect of trust in seller on purchase intention, revealing recommendation intention, rather than trust in seller, leads to purchase intention. The result also explains why H8 is not supported. 
Table 3. Results of test on mediating effects.

\begin{tabular}{llllc}
\hline \multicolumn{1}{c}{ Mediation Paths } & Direct Effects & Indirect Effects & Total Effects & VAF \\
\hline Ganqing $\rightarrow$ TRIS $\rightarrow$ REC & $0.149\left(2.029^{*}\right)$ & $0.194\left(3.332^{* * *}\right)$ & $0.342\left(4.006^{* * *}\right)$ & 0.567 \\
Renqing $\rightarrow$ TRIS $\rightarrow$ REC & $0.185\left(2.926^{* *}\right)$ & $0.102(1.884)$ & $0.286\left(3.686^{* * *}\right)$ & 0.357 \\
Mianzi $\rightarrow$ TRIS $\rightarrow$ REC & $0.011(0.189)$ & $0.206\left(4.841^{* * *}\right)$ & $0.217\left(3.215^{* * *}\right)$ & 0.949 \\
Ganqing $\rightarrow$ REC $\rightarrow$ PI & $0.011(0.123)$ & $0.078(1.840)$ & $0.207\left(2.325^{*}\right)$ & 0.377 \\
Renqing $\rightarrow$ REC $\rightarrow$ PI & $0.214\left(2.447^{* *}\right)$ & $0.097\left(2.838^{* *}\right)$ & $0.373\left(4.622^{* * *}\right)$ & 0.260 \\
Mianzi $\rightarrow$ REC $\rightarrow$ PI & $0.008(0.132)$ & $0.006(0.185)$ & $0.140\left(2.041^{*}\right)$ & 0.043 \\
TRIS $\rightarrow$ REC $\rightarrow$ PI & $0.051(0.622)$ & $0.310\left(5.560^{* * *}\right)$ & $0.361\left(5.224^{* * *}\right)$ & 0.859 \\
\hline
\end{tabular}

Note: $\mathrm{REC}=$ recommendation intention; PI = purchase intention; TRIS $=$ trust in seller. T Statistics are in parentheses. *** $p<0.001 ; * * p<0.01 ; * p<0.05$.

Moreover, buyer's purchase intention is based mainly on recommendation intentions $(\beta=0.525$, $p<0.000$ ), and it mediates the most effect of trust in seller on purchase intention (variance accounted for, VAF $=0.859$ ). That might be the main reason why $\mathrm{H} 8$ is not supported. Thus, to encourage recommendation intention, renging should be the most critical route to stimulate the purchase intention. Ganqing and mianzi concern can help facilitate recommendation intention via trust in seller. Although trust in seller is not the cause of purchase intention, it still plays as a major facilitator for recommendation intention and transforms ganqing or mianzi into recommendation intention. Kucukemiroglu and Kara [70] found that social capital and trust positively influence opinion-giving/seeking behavior, which in turn positively influences WOM behavior on Facebook. The results concur with Kucukemiroglu and Kara's [70] findings and reveal that trust in seller leads to recommendation intention (i.e., intention of posting positive online WOM) and further contributes to purchase intention through recommendation intention. In addition, the results demonstrate the leading role of recommendation intention in generating purchase intention, and the critical indicator of purchase intention in the context of interpersonal communicating and selling on social media. According to Wang et al. [21], buyers' recommendation intentions could be regarded as a type of buyer-seller guanxi investment, which results from ganqing, renqing, mianzi and xinyong (credibility) between parties, since the buyer's recommendation represent his (her) willingness to endorse and guarantee the seller' products/services and that might cost the buyer some efforts and reputation. The results prove the buyer's recommendation intention to be the consequences of buyer-seller ganqing and renqing and trust in seller. Finally, the control variable PDI is positively related to purchase intention $(\beta=0.347, p<0.001)$ and its effect is greater than renqing $(\beta=0.214, p<0.01)$, implying that PDI facilitates purchase intention and renqing exerts a limited effect on purchase intention due to PDI.

\section{Conclusions and Implications}

This study adopts the concept of traditional guanxi to portray the online buyer-seller guanxi, and further investigates the roles of buyer's perception of buyer-seller guanxi facets in social commerce. The results have some implications for the field of social commerce in the Chinese culturally rooted society.

\subsection{Theoretical Implications}

First, the results confirm that the buyer's perceptions of traditional guanxi facets still function, and each of them, i.e., ganqing, renqing, and mianzi, still facilitates the trust in seller. Ganqing and renqing boost the buyer's recommendation intention on social media. Second, being different from prior studies, this study also confirms the mediating role of recommendation intention between renqing and purchase intention and the mediating role of trust in seller between ganqing/mianzi and recommendation intention. In the advent of social commerce, the consumer-generated social influence, which comes from user recommendations and referrals, has been an important tool to boost sales in social commerce [12,13]. This study confirms the buyer's perception of ganqing, renqing and trust in seller plays important antecedents of social influence-recommendation. This study also clarifies the 
mediating role of trust in seller between buyer-seller guanxi facets and recommendation intention and confirms the influence path and effect of each guanxi facet on trust in seller. Third, compared with prior studies, this study further confirms that recommendation intention replaces the most effect of trust in seller on purchase intention as the main role in leading to purchase intention.

Fourth, to the best of our knowledge, little academic research has demonstrated the influence of mianzi at the interpersonal level in social commerce. Although mianzi concern does not function as expected in provoking recommendation intention, it is still positively related to trust in seller, supporting that buyer's concern over seller's mianzi tends to be the affirmation and acknowledgment of trust in seller, which includes seller's ability, integrity, and benevolence. Fifth, recommendation intention is an important interface of transferring guanxi facets and trust in seller into purchase intention. However, renqing exerts a direct positive impact on purchase intention, highlighting the vital function of renqing in facilitating purchase intention. Finally, this study confirms PDI does play a critical role in facilitating purchase intention and its impact is even greater than renqing, implying PDI is beneficial for boosting purchase intention.

\subsection{Practical Implications}

Social media has been a critical tool to promote personal sales business and transform friendship into business relationship, especially for those salespeople who have just begun their sales careers and have not got many connections or are not involved in many guanxi networks. According to the results, the activities of cultivating buyer-seller guanxi facets through social media and related technologies are required to help gain the buyer's trust in seller and willingness to recommend the seller's posts, which in turn boost the purchase intention. For example, establishing, maintaining and reinforcing the buyer-seller ganqing through social media still works well. Social media related technology acumen, broader skill and gamification sensibility are also required while implementing these social media ganqing activities — continuous greeting, high-quality/up-to-date information sharing, private chatting/ending well, and favors exchanging with younger customers. A seller has to embrace and utilize social media-related technologies and skills to drive younger/potential buyers to social media, enforce the efforts of social media ganqing activities [71], and facilitate the buyer's intrinsic motives to share with friends due to the value of hedonism, fun and game [72]. Only renqing can directly benefit purchase intention in social commerce. Then, taking buyer's request for small favors, passing along monopolized/useful information, and helping/inducing buyers to make connections with other potential buyers through social media activities does not just contribute to purchase intention but also to satisfying the buyer's needs of renqing exchange [8]. To give/save the buyer's mianzi through responding quickly and positively to his/her voices/questions or using inspiration and ingratiation tactics/complements to cheer his/her social media commons/engagements also contribute to trust in seller. In addition, to show empathy and personal care often to the buyer, will induce the buyer to follow the obligation/reciprocity rules and that will lead to better communication between parties. Through these social media guanxi activities, the buyer-seller guanxi will be more solid and can facilitate recommendations and trust in seller, which in turn creates significant opportunities for boosting sales.

However, the results also remind the seller of a fact that no matter how successful in cultivating buyer-seller guanxi facets, without the recommendation intention, only one of these guanxi facets—renqing—can benefit purchase intention directly. Thus, facilitating or encouraging buyer's willingness to recommend the seller's offering will be the key to create great opportunities to transform these guanxi facets into the real sales in the context of social commerce. This study suggests recommendation intention plays as a leading indicator of purchase intention better than a buyer's trust in seller, and the purpose of cultivating guanxi should be facilitating recommendation intention. The results also indicate that the mianzi concern should not be expected to benefit the consumer's recommendation intention. Instead, it contributes to trust in seller. The seller has to find other ways to promote the consumer's willingness to recommend the seller's products or services, not just counting on ganqing and renqing activities. However, its impact on trust in seller should not be ignored, 
and the seller should target those people in a guanxi network who perceive the seller's trustworthiness, credibility or reputation. Finally, the seller should be aware of the critical role of PDI in boosting purchase intention. Identifying target buyers who are highly involved in PDI could be beneficial and a good starting point. The seller should also construct a highly capable professional image, convince buyers to be more concerned about their purchase decisions, and then boost their guanxi support.

In modern social commerce, guanxi is no longer everything, however, it really does something according to this study. This study portrays a map to guide Westerners or businesspeople with different cultures who want to enter the business in the Chinese culturally rooted social commerce. The Western conventions, e.g., social tie, relationship quality, benevolence, etc., might just explain partial ideologies of people in Chinese social commerce. This study demonstrates that to understand these guanxi rules and adapt them to the online social commerce in the Chinese context will be the "alternative road leading to Rome."

\subsection{Limitations and Suggestions for Future Research}

There are some limitations, which deserve future research. First, future research can compare the impact of guanxi with other contingent variables on social media, such as seller's social influences [73], social presence [35], media richness [74] or the personal characteristics of consumers. Second, since the buyer makes the purchase decision and the buyer is best positioned to judge if buyer-seller guanxi exists, this study follows most of the guanxi research carried out on only one side of the guanxi. Future research can adopt the seller's perspective or a dyadic perspective to explore whether the gaps or differences between two sides influence purchase intention during the interaction. Finally, the availability of large-scale data enables a comprehensive analysis of the impact of guanxi. It would be helpful to use data from other countries in Confucian Asia to detect fundamental differences or test the hypotheses and improve the generalizability of the results.

Funding: This research was funded by Ministry of Science and Technology, Taiwan, grant number 108-2410-H-324-011.

Conflicts of Interest: The authors declare no conflict of interest. The funders had no role in the design of the study; in the collection, analyses, or interpretation of data; in the writing of the manuscript, or in the decision to publish the results.

\section{Appendix A. Measurement Scales and Results of Factor Analysis}

\section{Ganqing $[22,23,47]$}

- I often feel very happy and comfortable when chatting with him (her) on social media a

- We are able to talk openly on social media as close friends ${ }^{a}$

- I am very prepared to help him (her) whenever he (she) needs

- We treat each other like a couple of good or old friends

- I have a feeling or brotherhood for him (her)

(Cronbach's Alpha $=0.891$, Composite Reliability $=0.932, A V E=0.821$.

\section{Renqing $[23,47,75]$}

- Our relationship is based on helpfulness and repayment

- The practice of give and take of favors is a key part of the relationship

- I desire to return him (her) for his (her) favors

- I feel a sense of obligation for doing him (her) a favor ${ }^{a}$

- I feel very sorry if I cannot help him (her) ${ }^{\mathrm{a}}$

(Cronbach's Alpha $=0.869$, Composite Reliability $=0.912, A V E=0.724)$.

Mianzi [21,22] 
- I never criticize him (her) on social media ${ }^{b}$

- I think my positive comments on social media will protect or improve his (her) face

- I think my negative comments on social media will damage his (her) face

- I will give high priority to his (her) invitation

- Protecting his (her) face on social media is very important

(Cronbach's Alpha $=0.901$, Composite Reliability $=0.931, A V E=0.771)$.

Trust in seller [5] (Formative construct)

- He (she) is very knowledgeable and competent about his (her) products or services

- I think he (she) is an honest seller of complete integrity.

- I believed that he (she) would act in my best interests.

(The formative indicator weights range from 0.151 to 0.509 and exert distinct effects. All VIFs range from 2.193 to 2.792 and are less than the threshold of 10).

\section{Recommendation intention $[70,76]$}

- I would like to introduce the products or services to my social media friends

- I want to share the products or services with my social media friends

- I want to recommend the products or services to my social media friends

- I will persuade others to buy the products or services ${ }^{c}$

(Cronbach's Alpha $=0.877$, Composite Reliability $=0.925, A V E=0.803)$.

\section{Purchase intention $[3,35]$}

- I will certainly buy the products or services due to his (her) posts on social media

- I will purchase the products or services from him (her) next time

- I definitely will think about buying the products or services from him (her) when I need

(Cronbach's Alpha $=0.801$, Composite Reliability $=0.883$, AVE $=0.716)$.

\section{Purchase-Decision Involvement [77-79]}

- I am very careful and watchful before buying the products or services

- I see the high risk when buying the products or services

- I have to spend much time to understand the products or services.

- I found these products or services to be unfamiliar ${ }^{\mathrm{c}}$

(Cronbach's Alpha $=0.862$, Composite Reliability $=0.900, A V E=0.751)$.

Note:

a The item was excluded because the item loaded on the factors other than on the intended factor.

b The item was excluded because the item did not load on the factor for which it was originally intended.

c The item was excluded due to its indicator loading is lower than 0.55 [80].

\section{References}

1. Busalim, A.H.; Hussin, A.R.C.; Iahad, N.A. Factors Influencing Customer Engagement in Social Commerce Websites: A Systematic Literature Review. J. Theor. Appl. Electron. Commer. Res. 2019, 14, 1-14. [CrossRef] 
2. Lin, J.; Li, L.; Yan, Y.; Turel, O. Understanding Chinese Consumer Engagement in Social Commerce. Internet Res. 2018, 28, 2-22. [CrossRef]

3. Li, Q.; Liang, N.; Li, E.Y. Does Friendship Quality Matter in Social Commerce? an Experimental Study of Its Effect on Purchase Intention. Electron. Commer. Res. 2018, 18, 693-717. [CrossRef]

4. Hwang, K.-K. Face and Favor: The Chinese Power Game. Am. J. Sociol. 1987, 92, 944-974. [CrossRef]

5. Ou, C.X.; Pavlou, P.A.; Davison, R.M. Swift Guanxi in Online Marketplaces: The Role of Computer-Mediated Communication Technologies. MIS Q. 2014, 38, 209-230. [CrossRef]

6. Shi, S.; Mu, R.; Lin, L.; Chen, Y.; Kou, G.; Chen, X.-J. The Impact of Perceived Online Service Quality on Swift Guanxi. Internet Res. 2018, 28, 432-455. [CrossRef]

7. Fei, X.T. From the Soil: The Foundations of Chinese Society; University of California Press: Berkeley, CA, USA, 1992.

8. Niedermeier, K.E.; Wang, E.; Zhang, X. The Use of Social Media among Business-to-Business Sales Professionals in China. J. Res. Interact. Mark. 2016, 10, 33-49. [CrossRef]

9. Agnihotri, R.; Dingus, R.; Hu, M.Y.; Krush, M.T. Social Media: Influencing Customer Satisfaction in B2B Sales. Ind. Mark. Manag. 2016, 53, 172-180. [CrossRef]

10. Keinänen, H.; Kuivalainen, O. Antecedents of Social Media B2B Use in Industrial Marketing Context: Customers' View. J. Bus. Ind. Mark. 2015, 30,711-722. [CrossRef]

11. Kumar, A.; Bezawada, R.; Rishika, R.; Janakiraman, R.; Kannan, P. From Social to Sale: The Effects of Firm-Generated Content in Social Media on Customer Behavior. J. Mark. 2016, 80, 7-25. [CrossRef]

12. Pescher, C.; Reichhart, P.; Spann, M. Consumer Decision-making Processes in Mobile Viral Marketing Campaigns. J. Interact. Mark. 2014, 28, 43-54. [CrossRef]

13. Kim, N.; Kim, W. Do Your Social Media Lead You to Make Social Deal Purchases? Consumer-Generated Social Referrals for Sales via Social Commerce. Int. J. Inf. Manag. 2018, 39, 38-48. [CrossRef]

14. Chiu, T.-S.; Chih, W.-H.; Ortiz, J.; Wang, C.-Y. The Contradiction of Trust and Uncertainty from the Viewpoint of Swift Guanxi. Internet Res. 2018, 28, 716-745. [CrossRef]

15. Chen, X.-P.; Chen, C.C. On the Intricacies of the Chinese Guanxi: A Process Model of Guanxi Development. Asia Pac. J. Manag. 2004, 21, 305-324. [CrossRef]

16. Farh, J.-L.; Tsui, A.S.; Xin, K.; Cheng, B.-S. The Influence of Relational Demography and Guanxi: The Chinese Case. Organ. Sci. 1998, 9, 471-488. [CrossRef]

17. Gu, F.F.; Hung, K.; Tse, D.K. When Does Guanxi Matter? Issues of Capitalization and Its Dark Sides. J. Mark. 2008, 72, 12-28. [CrossRef]

18. Lin, J.; Si, S.X. Can Guanxi Be a Problem? Contexts, Ties, and Some Unfavorable Consequences of Social Capital in China. Asia Pac. J. Manag. 2010, 27, 561-581. [CrossRef]

19. Fletcher-Chen, C.C.-Y.; Al-Husan, F.B.; Alhussan, F.B. Relational Resources for Emerging Markets' Non-Technological Innovation: Insights from China and Taiwan. J. Bus. Ind. Mark. 2017, 32, 876-888. [CrossRef]

20. Chen, M.-H.; Chang, Y.-Y.; Lin, Y.-C. Exploring Creative Entrepreneurs' Happiness: Cognitive Style, Guanxi and Creativity. Int. Entrep. Manag. J. 2018, 14, 1089-1110. [CrossRef]

21. Wang, G.; Wang, X.; Zheng, Y. Investing in Guanxi: An Analysis of Interpersonal Relation-Specific Investment (RSI) in China. Ind. Mark. Manag. 2014, 43, 659-670. [CrossRef]

22. Chen, L.; Chin, F.G.; Sun, Y.; Amran, R. Integrating Guanxi Into Technology Acceptance: An Empirical Investigation of WeChat. Telemat. Inform. 2017, 34, 1125-1142.

23. Barnes, B.R.; Yen, D.; Zhou, L. Investigating Guanxi Dimensions and Relationship Outcomes: Insights from Sino-Anglo Business Relationships. Ind. Mark. Manag. 2011, 40, 510-521. [CrossRef]

24. Wong, Y.H.; Chan, R.Y.-K. Relationship Marketing in China: Guanxi, Favouritism and Adaptation. J. Bus. Ethics 1999, 22, 107-118. [CrossRef]

25. Fang, T. Chinese Business Negotiating Style; Sage Publications: California, CA, USA, 1999.

26. Yang, X.; Ho, E.Y.-H.; Chang, A. Integrating the Resource-Based View and Transaction Cost Economics in Immigrant Business Performance. Asia Pac. J. Manag. 2010, 29, 753-772. [CrossRef]

27. Tsui, A.S.; Farh, J.-L.L. Where Guanxi Matters. Work Occup. 1997, 24, 56-79. [CrossRef]

28. Chen, C.C.; Chen, Y.-R.; Xin, K. Guanxi Practices and Trust in Management: A Procedural Justice Perspective. Organ. Sci. 2004, 15, 200-209. [CrossRef]

29. Sternuist, B.; Chen, Z. Food Retail Buyer Behavior in People's Republic of China: A Grounded Theory Model. Qual. Mark. Res. Int. J. 2006, 9, 243-265. [CrossRef] 
30. Wong, H.Y.; Leung, T. Guanxi: Relationship Marketing in a Chinese Context; International Business Press: Binghamton, NY, USA, 2001.

31. Michailova, S.; Worm, V. Personal Networking in Russia and China:: Blat and Guanxi. Eur. Manag. J. 2003, 21, 509-519. [CrossRef]

32. Standifird, S.S.; Marshall, R. The Transaction Cost Advantage of Guanxi-Based Business Practices. J. World Bus. 2000, 35, 21-42. [CrossRef]

33. Lin, J.; Yan, Y.; Chen, S.; Luo, X. Understanding the Impact of Social Commerce Website Technical Features on Repurchase Intentions: A Chinese Guanxi Perspective. J. Electron. Commer. Res. 2017, 18, 225-244.

34. Xiang, L.; Zheng, X.; Lee, M.K.; Zhao, D. Exploring Consumers' Impulse Buying Behavior on Social Commerce Platform: The Role of Parasocial Interaction. Int. J. Inf. Manag. 2016, 36, 333-347. [CrossRef]

35. Al-Adwan, A.S.; Kokash, H. The Driving Forces of Facebook Social Commerce. J. Theor. Appl. Electron. Commer. Res. 2019, 14, 15-32. [CrossRef]

36. Lu, B.; Fan, W.; Zhou, M. Social Presence, Trust, and Social Commerce Purchase Intention: An Empirical Research. Comput. Hum. Behav. 2016, 56, 225-237. [CrossRef]

37. Davison, R.M.; Ou, C.X.; Martinsons, M.G. Interpersonal Knowledge Exchange in China: The Impact of Guanxi and Social Media. Inf. Manag. 2018, 55, 224-234. [CrossRef]

38. Itani, O.S.; Agnihotri, R.; Dingus, R. Social Media Use in B2B Sales and Its Impact on Competitive Intelligence Collection and Adaptive Selling: Examining the Role of Learning Orientation as an Enabler. Ind. Mark. Manag. 2017, 66, 64-79. [CrossRef]

39. Rapp, A.; Beitelspacher, L.S.; Grewal, D.; Hughes, D.E. Understanding Social Media Effects Across Seller, Retailer, and Consumer Interactions. J. Acad. Mark. Sci. 2013, 41, 547-566. [CrossRef]

40. Wang, J.-C.; Chang, C.-H. How Online Social Ties and Product-Related Risks Influence Purchase Intentions: A Facebook Experiment. Electron. Commer. Res. Appl. 2013, 12, 337-346. [CrossRef]

41. Zhang, Z.; Wang, H. How Online Social Ties and Product-Related Factors Influence Purchasing Intention in Mobile Social Commerce Context. Int. J. Mob. Commun. 2019, 17, 191. [CrossRef]

42. Featherman, M.S.; Hajli, N. Self-Service Technologies and e-Services Risks in Social Commerce Era. J. Bus. Ethics 2015, 139, 251-269. [CrossRef]

43. Gefen, D.; Straub, D.W. Consumer Trust in B2C E-Commerce and the Importance of Social Presence: Experiments in e-Products and e-Services. Omega 2004, 32, 407-424. [CrossRef]

44. Shaalan, A.; Reast, J.; Johnson, D.; Tourky, M.E. East Meets West: Toward a Theoretical Model Linking Guanxi and Relationship Marketing. J. Bus. Res. 2013, 66, 2515-2521. [CrossRef]

45. Kim, Y.H.; Kim, D.J.; Wachter, K. A Study of Mobile User Engagement (Moen): Engagement Motivations, Perceived Value, Satisfaction, and Continued Engagement Intention. Decis. Support Syst. 2013, 56, 361-370. [CrossRef]

46. VanMeter, R.A.; Grisaffe, D.B.; Chonko, L.B. Of "Likes" and "Pins": The Effects of Consumers' Attachment to Social Media. J. Interact. Mark. 2015, 32, 70-88. [CrossRef]

47. Berger, R.; Herstein, R.; Silbiger, A.; Barnes, B.R. Can Guanxi Be Created in Sino-Western Relationships? an Assessment of Western Firms Trading with China Using the GRX Scale. Ind. Mark. Manag. 2015, 47, 166-174. [CrossRef]

48. Dong, X.; Wang, T. Social Tie Formation in Chinese Online Social Commerce: The Role of It Affordances. Int. J. Inf. Manag. 2018, 42, 49-64. [CrossRef]

49. Choi, C.; Berger, R.; Kim, J. Globalization, Property Rights and Knowledge Networks. Int. J. Technol. Manag. 2011, 56, 53-72. [CrossRef]

50. Redding, S.G. The Spirit of Chinese Capitalism; Walter de Gruyter GmbH: New York, NY, USA, 1990.

51. Shou, Z.; Guo, R.; Zhang, Q.; Su, C. The Many Faces of Trust and Guanxi Behavior: Evidence from Marketing Channels in China. Ind. Mark. Manag. 2011, 40, 503-509. [CrossRef]

52. Leung, T.; Chan, R.Y.K.; Lai, K.-H.; Ngai, E.W. An Examination of the Influence of Guanxi and Xinyong (Utilization of Personal Trust) on Negotiation Outcome in China: An Old Friend Approach. Ind. Mark. Manag. 2011, 40, 1193-1205. [CrossRef]

53. Chen, Y.L.; Tang, K.; Wu, C.C.; Jheng, R.Y. Predicting the Influence of Users' Posted Information for eWON Advertising in Social Networks. Electron. Commer. Res. Appl. 2014, 13, 431-439. [CrossRef] 
54. Zeng, F.; Huang, L.; Dou, W. Social Factors in User Perceptions and Reponses to Advertising in Online Social Networking Communities. J. Interact. Advert. 2009, 10, 1-13. [CrossRef]

55. Zaichkowsky, J.L. The Personal Involvement Inventory: Reduction, Revision, and Application to Advertising. J. Advert. 1994, 23, 59-70. [CrossRef]

56. Petty, R.E.; Cacioppo, J.T.; Schumann, D. Central and Peripheral Routes to Advertising Effectiveness: The Moderating Role of Involvement. J. Consum. Res. 1983, 10, 135-146. [CrossRef]

57. Petty, R.E.; Cacioppo, J.T.; Strathman, A.J.; Priester, J.R. To Think or Not to Think: Exploring Two Routers to Persuation. In Persuation: Psychological Insights and Perspectives; Brock, T.C., Green, M.C., Eds.; Sage: Thousand Oaks, CA, USA, 2005; pp. 81-116.

58. Simon, K. Latest Digital in 2018 Global Report. Available online: https://wearesocial.com/blog/2018/01/ global-digital-report-2018 (accessed on 6 October 2018).

59. Chin, W.W. How to Write Up and Report PLS Analyses. In Handbook of Partial Least Squares; Esposito, V.V., Chin, W.W., Henseler, J., Wang, H., Eds.; Springer: Berlin/Heidelberg, Germany, 2009; pp. 655-690.

60. Rigdon, E.E. Choosing PLS Path Modeling as Analytical Method in European Management Research: A Realist Perspective. Eur. Manag. J. 2016, 34, 598-605. [CrossRef]

61. Fornell, C.; Bookstein, F.L. A Comparative Analysis of Two Structural Equation Model: LISERL and PLS Applied to Market Data. In A Second Generation of Multivariate Analysis; Praeger: New York, NY, USA, 1982.

62. Ringle, C.; Wende, S.; Becker, J.-M. SmartPLS 3; SmartPLS GmbH: Boenningstedt, Germany, 2015.

63. Fornell, C.; Larcker, D.F. Evaluating Structural Equation Models with Unobservable Variables and Measurement Error. J. Mark. Res. 1981, 18, 39. [CrossRef]

64. Podskoff, P.M.; Mackenzie, S.B.; Lee, J.Y.; Podsakoff, N.P. Common Method Biases in Behavioral Research: A Critical Review of the Literature and Recommended Remedies. J. Appl. Psychol. 2003, 88, 879. [CrossRef] [PubMed]

65. Harman, H.H. Modern Factor the Analysis; University of Chicago Press: Chicago, IL, USA, 1967.

66. Podsakoff, P.M.; Organ, D.W. Self-Reports in Organizational Research: Problems and Prospects. J. Manag. 1986, 12, 531-544. [CrossRef]

67. Kock, N. Common Method Bias in PLS-SEM. Int. J. e-Collab. 2015, 11, 1-10. [CrossRef]

68. Hair, J.F.; Hult, G.; Ringle, C.; Sarstedt, M. A Primer on Partial Least Squares Structural Equation Modeling (PLS-SEM), 2nd ed.; Sage: Thousand Oaks, CA, USA, 2017.

69. Chong, A.Y.L.; Lacka, E.; Boying, L.; Chan, H.K. The Role of Social Media in Enhancing Guanxi and Perceived Effectiveness of E-Commerce Institutional Mechanisms in Online Marketplace. Inf. Manag. 2018, 55, 621-632. [CrossRef]

70. Kucukemiroglu, S.; Kara, A. Online Word-of-Mouth Communication on Social Networking Sites. Int. J. Commer. Manag. 2015, 25, 2-20. [CrossRef]

71. Moncrief, W.C.; Marshall, G.W.; Rudd, J.M. Social Media and Related Technology: Drivers of Change in Managing the Contemporary Sales Force. Bus. Horiz. 2015, 58, 45-55. [CrossRef]

72. Vilnai-Yavetz, I.; Levina, O. Motivating Social Sharing of E-Business Content: Intrinsic Motivation, Extrinsic Motivation, or Crowding-Out Effect? Comput. Hum. Behav. 2018, 79, 181-191. [CrossRef]

73. Hsieh, J.; Tseng, C. Exporing Social Influence on Hedonic Buying of Digital Goods—Online Game's Virtual Items. J. Electron. Commer. Res. 2018, 19, 164-185.

74. Shao, Z.; Pan, Z. Building Guanxi Network in the Mobile Social Platform: A Social Capital Perspective. Int. J. Inf. Manag. 2019, 44, 109-120. [CrossRef]

75. Yen, D.A.; Barnes, B.R.; Wang, C.L. The Measurement of Guanxi: Introducing the GRX Scale. Ind. Mark. Manag. 2011, 40, 97-108. [CrossRef]

76. Nel, J.; Halaszovich, T. The Influence of Satisfaction on Facebook Fan Page 'Like' Intentions. Manag. Dyn. 2015, 24, 26-40.

77. Mittal, B. Measuring Purchase-Decision Involvement. Psychol. Mark. 1989, 6, 147-162. [CrossRef]

78. Cucchiara, C.; Kwon, S.; Ha, S. Message Framing and Consumer Responses to Organic Seafood Labeling. Br. Food J. 2015, 117, 1547-1563. [CrossRef] 
79. Voyer, P.A.; Ranaweera, C. The Impact of Word of Mouth on Service Purchase Decisions. J. Serv. Theory Pract. 2015, 25, 636-656. [CrossRef]

80. Falk, R.F.; Miller, N.B. A primer for soft modeling; University of Akron Press: Akron, OH, USA, 1992.

Publisher's Note: MDPI stays neutral with regard to jurisdictional claims in published maps and institutional affiliations.

(C) 2020 by the author. Licensee MDPI, Basel, Switzerland. This article is an open access article distributed under the terms and conditions of the Creative Commons Attribution (CC BY) license (http://creativecommons.org/licenses/by/4.0/). 